\title{
COLOBOMA OF THE OPTIC NERVE WITH REMAINS OF THE HYALOID ARTERY
}

BY

J. Rosenbaum, M.D.

MONTREAL

Mrs. C. G., aged 32 years, came to the Herzl Dispensary, Montreal, on January 15,1925 , complaining of defective vision of the right eye.

Examination :-Right eye, divergent strabismus (non-paralytic) $30^{\circ}$. Pupil circular, and active to light and accommodation. The fundus revealed the following : Increase of the surface of the optic disc to about twice the normal size, and its site was occupied by a greyish-white funnel-shaped cavity. The temporal margin of the funnel shows masses of black pigment, while at the nasal margin there are one or perhaps two specks of pigment. From about the middle of the nasal side of the funnel there is the remains of a hyaloid artery floating in the vitreous in the form of a connective tissue tag. The retinal vessels below and to the nasal side disappear sharply at the edge, while those above can be followed for some distance. The field of vision is normal except that the blind spot

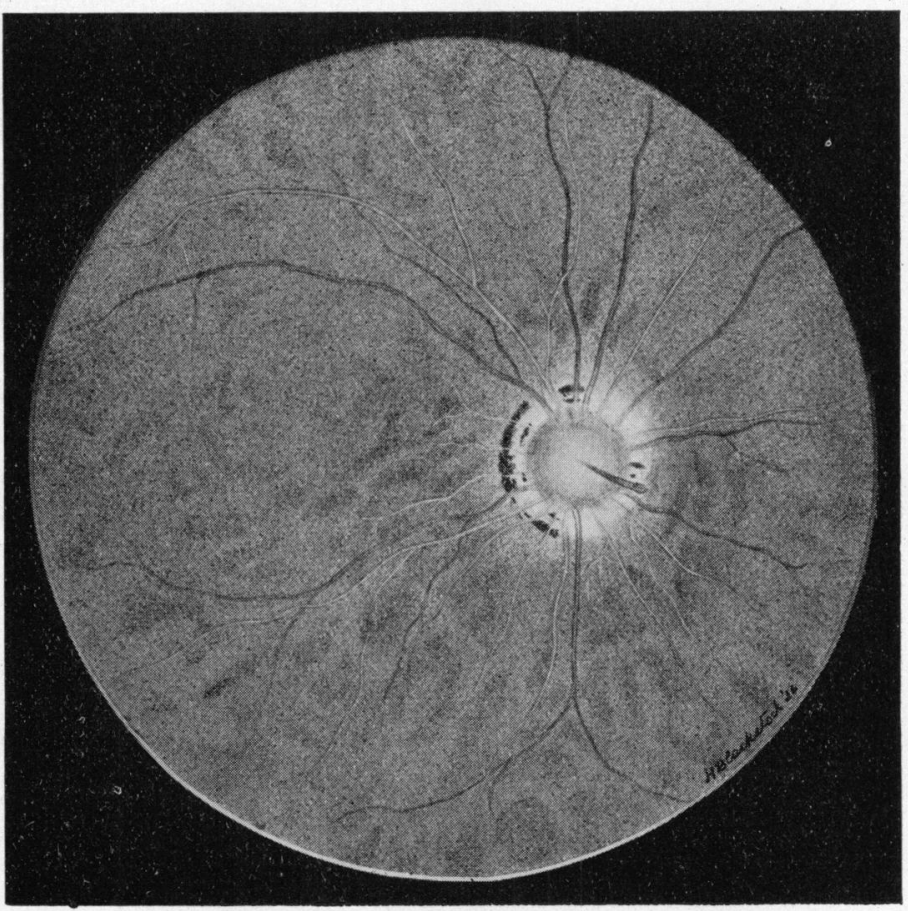


extends from the fixation point outward $25^{\circ}$. Vision $=$ fingers at 4 feet.

The fundus of the left eye is normal. Vision $=6 / 6$.

\section{ANNOTATION}

\section{The Ciliary Muscle}

It is usually held that the discovery of the ciliary muscle was made simultaneously by Sir William Bowman and Professor Bruecke. Their discovery was independent of each other; and Bowman announced his views at a meeting of the British Association, held at Oxford in 1847.

In this connection it is curious that the priority of the discovery of the true nature of the ciliary muscle by Knox, the celebrated extramural teacher of anatomy at Edinburgh, has been entirely overlooked.

Knox read a paper on "The Comparative Anatomy of the Eye," before the Royal Society at Edinburgh, on June 17, 1823.

In this paper Knox tried to demonstrate that the adaptation of the eye to varying distances is effected by the ciliary muscle, "or that body which anatomists have hitherto called the ciliary ligament." In the "Life of Knox," by Lonsdale, from which we quote, it is stated that: "Though furnished only with a simple lens, he maintained that the Annulus albus showed no ligamentous fibres. but comparatively large branches of nerves; that it did not resemble any of the textures of the eyeball except the iris, but that here the resemblance was so close that they could with difficulty be distinguished." "Having discovered that in birds, and in the deer, the so-named (ciliary) ligament received numerous nerves, that its texture bore no resemblance whatever to ligament, that it became rudimentary in those animals whose sight was feeble, which would not necessarily happen were it simply a ligament for the suspension of the tunics and humours of the eye, the conclusion was irresistible that the Annulus albus is a muscle, that it is the muscle by which the eye adapts itself to the perception of distant objects; and that by it, in conjunction with the iris, all the changes which take place in the interior of the eyeball are effected."

Knox remarked that "the development of the ciliary muscle followed the ratio of the strength of vision, or rather of the accommodating powers of the eye in the various classes of animals; id est, it is strong in birds, in man, in the quadrumana, and in the deer; weaker in some others of the ruminantia, as the ox; still more so in the horse. Lastly, in most fishes it is completely rudimentary, and is reduced to a mere ligament." 